\title{
A Psicologia Ambiental e as Diversas REALIDADE HUMANAS
}

\author{
Esther Wiesenfeld ${ }^{1}$ \\ Instituto de Psicologia - Universidade Central de Venezuela
}

\begin{abstract}
Este artigo baseia as respostas quanto ao objeto da psicologia ambiental e seus aspectos constitutivos na análise dos periódicos Environment \& Behavior, Journal of Environmental Psychology, congressos e estudos latino-americanos. Considera que a definição do objeto, circunscrita a perspectivas que diferem emsuas dimensões ontológicas, epistemológicas e metodológicas, ocasiona várias psicologias ambientais. Para contribuir para o desenvolvimento do conhecimento e favorecer as condições de vida e do planeta, as distintas psicologias ambientais deveriam dialogar. Conclui que o enfoque adotado é que levaria a abordar a realidade de modos distintos.
\end{abstract}

Descritores: Psicologia ambiental. Objeto. Análise de conteúdo. Periódicos.

E $\mathrm{m}$ primeiro lugar, quero felicitar as coordenadoras deste simpósio pela organização do evento. As temáticas propostas, assim como a diversidade de países representados na exposição das mesmas, constituirá, sem dúvida, um marco na Psicologia Ambiental, do qual serão protagonistas todos os presentes. Também quero felicitá-las porque organizar um evento como este, dadas as sérias dificuldades econômicas que atualmente enfrentam nossos países latino-americanos, não é tarefa fácil.

1 Professora do Instituto de Psicologia e coordenadora dos programas de Mestrado e de Especialização em Intervenção Psicossocial da Universidade Central da Venezuela. Editora Associada do Journal of Commnunity and Applied Social Psychology. Endereço eletrônico: ewiesen@ reacciun.ve 
Pelas razões anteriores e pela maravilhosa oportunidade que me brindam de participar com vocês neste simpósio, sinto-me muito agradecida. Estou segura de que todos sairemos enriquecidos com os debates que aqui sejam suscitados, com novos conhecimentos e, sobretudo, com muitas inquietudes a ser canalizadas em nosso fazer como psicólogos ambientais.

\section{Objeto da Psicologia Ambiental e aspectos constitutivos desse objeto}

Vou me referir agora ao tema 1, cuja primeira pergunta trata do objeto da Psicologia Ambiental e dos aspectos da realidade que constituem esse objeto.

Perguntar-se a respeito do objeto, quer dizer, o que é, é perguntar-se a respeito da ontologia ou natureza do objeto. E responder a isto implica referir-se às posturas meta-teóricas ou paradigmáticas em que se fundamentam as diversas formas de concebê-lo e às estratégias metodológicas empregadas para a construção do conhecimento a respeito do dito objeto. Quer dizer, falar da ontologia de um objeto implica também falar em como nos aproximamos do objeto para conhecê-lo e em como construímos tal conhecimento.

Para tratar estas questões no campo da Psicologia Ambiental, irei me referir em primeiro lugar a: a) quais têm sido os principais objetivos da disciplina, isto é, o que se propôs, particularmente: ao que o seu objeto de estudo se refere, b) o que foi alcançado com respeito a tais aspirações, e c) que reflexões, lições e/ou recomendações podemos derivar da análise realizada.

\section{A que se propôs a Psicologia Ambiental}

A Psicologia Ambiental tem sido definida como a disciplina que estuda as transações entre as pessoas e seus entornos, com vistas a promover uma relação harmônica entre ambos, que redunde no bem-estar humano e na susteotabilidade ambiental.

Para cumprir esse propósito, os pioneiros da Psicologia Ambiental colocaram como objetos principais: 
- estudar a relação pessoa-ambiente no contexto natural, vista como totalidade (ontologia),

- abordar a dita relação de maneira holística (metodologia),

- incorporar diversas perspectivas teóricas em seu estudo (epistemologia),

- enfatizar a dimensão social da relação humano ambiental,

- estabelecer vínculos com outras disciplinas interessadas na temática humano ambiental (interdisciplinaridade),

- aplicar os conhecimentos obtidos para melhorar a qualidade ambiental e, por conseguinte, a qualidade de vida dos usuários dos ambientes (pertinência social).

A definição e objetivos da Psicologia Ambiental apontam pelo menos para dois objetos - pessoas e ambientes - que a disciplina tenta abarcar em sua diversidade.

Contudo, o modo de concebê-los, assim como os aspectos tratados em ambos os objetos, a ênfase em um e/ou em outro e a forma de entender e estudar sua relação, varia segundo a fundamentação teórica e metodológica assumida pelos profissionais, seus interesses e valores pessoais e institucionais, sua formação e experiência profissional, sua visão de mundo, o contexto de seu fazer e outros fatores, muitos dos quais conjunturais.

Os objetivos mencionados, formulados principalmente a partir da literatura psico-ambiental nos Estados Unidos, assemelham-se em grande medida aos que acompanharam os inícios da Psicologia Ambiental na Europa, embora as razões do surgimento da disciplina variaram em um e no outro contexto (Pol, 2001). Assim, enquanto a Psicologia Ambiental norteamericana teve como foco o indivíduo e a otimização de sua relação com o ambiente, a Psicologia Ambiental européia nasceu com forte vocação social, produto da crise social e habitacional da pós-guerra.

Do seu lado, os inícios da Psicologia Ambiental na América Latina foram, de modo marcante, influenciados pelos temas e enfoques adotados nos Estados Unidos, à margem de sua pertinência em nossa região. 


\section{O que aconteceu?}

Vejamos agora quais foram alguns dos aspectos mais freqüentemente abordados pela Psicologia Ambiental. Para isso nos basearemos, em primeiro lugar, na revisão dos temas tratados nos artigos publicados nos últimos seis anos (1997-2001, nos. 1 e 2) nas revistas Environment and Behavior (E \& B) e Journal of Environmental Psychology (JEP).

Também consideraremos os trabalhos desenvolvidos na América Latina, o que nos permitirá comparar a produção latino-americana com a de outras latitudes. Vamos nos apoiar, para esta análise, na revisão de Pinheiro (2001) com relação à Psicologia Ambiental no Brasil, na de Wiesenfeld (2001b), com base nos trabalhos latino-americanos apresentados até 1999 em diferentes encontros e publicações, as quais se somam as 21 apresentações em Psicologia Ambiental no Congresso Interamericano de Psicologia no Chile, 2001, e nas apresentações no II Encontro Latino-americano de Psicologia Ambiental ocorrido em setembro deste ano no México.

Sabemos que esta revisão não esgota a temática psicoambiental, mas constitui, a nosso ver, um aspecto representativo da mesma. Vejamos, então, o que trazem as revisões.

O total de 332 artigos publicados, 185 deles na revista E\&B e 147 na JEP, e as 191 apresentações nos últimos nove Congressos Interamericanos (1985-2001), mais os 120 apresentados nos dois Encontros Latinoamericanos de Psicologia Ambiental e alguns textos e artigos de autores latino-americanos, mostram uma ampla diversidade temática quanto à dimensão humana e quanto à ambiental.

Assim, contemplaram-se níveis distintos da escala humana (desde individual e comunitária até grandes conglomerados), tipos de autores, segundo sua etapa de desenvolvimento humano (crianças, adolescentes, adultos, idosos), gênero (homens, mulheres), variáveis demográficas e culturais (imigrantes, moradores de rua), usos de determinados ambientes (doentes no caso de hospitais, escolares no caso de instituições educativas, donas de casa no caso de entornos residenciais, empregados no caso de instituições de tra- 
balho), processos psicológicos, sociais e culturais (percepção, crenças, atit udes, representações sociais, experiências, preferências, identidade, apego, apropriação, sentido de lugar, comportamento pró-ambiental, condutas deterioradoras, avaliação pós-ocupação, compromisso ambiental, privacidade, territorialidade, bem-estar, interação social, reciclagem, diferenças culturais em alguns destes processos, participação cidadã).

Igualmente foram trabalhadas diferentes escalas do ambiente (desde micro como o espaço doméstico, intermediários como a vizinhança, até macro como a cidade), tipos de ambientes (residenciais, urbanos, rurais, recreativos, laborais, educativos, hospitalares), fatores ambientais específicos (design, decoração, ruído, iluminação, cor) ou gerais (qualidade ambiental) e processos ambientais (conservação ou deterioração, sustentabilidade, risco ambiental e desastres naturais).

Embora os autores dos artigos publicados nas revistas E\&B e JEP são, em sua maior parte, dos Estados Unidos ou trabalham nos Estados Unidos, também estão representados autores de outros países e continentes, sem que se identifique alguma preferência pelo tema ou o modo de abordagem segundo o contexto de procedência. Isto é, indistintamente podemos encontrar coincidências entre os temas de investigação entre autores latinoamericanos, norte-americanos, europeus ou africanos, assim como discrepâncias temáticas entre autores de um mesmo país. Mais ainda, identificamos temas similares porém tratados de diversas óticas, tanto teóricas quanto metodológicas, em um mesmo país ou entre países do mesmo ou diversos continentes. Por exemplo, o tema do ambiente residencial foi investigado com base nas atribuições sociais quanto ao interior da moradia, às propriedades visuais e às valorações afetivas das áreas residenciais, à interação social segundo a organização espacial da moradia, ao significado do lar, à avaliação da satisfação residencial, aos usos de diferentes espaços residenciais, à identidade de lugar, à percepção da qualidade do ambiente residencial, à relação entre privacidade e design, para citar alguns.

A variedade de aspectos estudados com respeito a um mesmo entorno em um mesmo país sugere que a seleção de tópicos de estudo ou de inter- 
venção em Psicologia Ambiental não deriva necessariamente de suas particularidades essenciais, ou das pessoas, ou da relação entre ambos. Tão pouco aponta para a preponderância de certos tópicos ou problemas discriminados por contextos (países, regiões ou continentes). Por exemplo, no México, Serafin Mercado e outros desenvolveram um modelo de habitabilidade residencial baseado em um modelo cognitivo comportamental, enquanto que Miguel Angel Aguilar tratou deste tema de uma perspectiva construtivista, e Bernardo Jimenez sugeriu o emprego da Investigação Ação Participativa, que corresponde a uma perspectiva teórico crítica.

A variedade resenhada parece antes sugerir que a eleição temática obedece a motivos que transcendem a especificidade psicoambiental, tais como inclinações pessoais. Além disto, como esta diversidade se expressa em um mesmo país, pode-se supor alguma ou todas as seguintes opções: a) que a eleição temática em questão ocorre à margem das demandas do contexto; b) que tais demandas ou prioridades são compreendidas de diversas maneiras pelos profissionais, e c) que os critérios para estabelecer as ditas prioridades são relativos. Deste modo, se a moradia é uma prioridade, deveriam existir certos indicadores que justifiquem tal prioridade, assim como orientações e critérios para enfrentá- la, mas isto não é o que costuma ocorrer.

Além disto, não se trata apenas de ignorar o contexto, ou da falta de correspondência entre as prioridades do investigador e as do contexto. Parece que a diversidade temática e intra-temática e as discrepâncias no modo de tratá-las, inclusive intra-país, ou o seu oposto, que dizer, algumas coincidências entre países, sugerem, adicionalmente, as seguintes considerações:

1. A ausência de um fio condutor ou de uma linha de investigações derivada do diálogo entre as demandas do contexto e os recursos, existentes ou potenciais, da Psicologia Ambiental para satisfazêlas. Em conseqüência, tão pouco existem delineamentos ou parâmetros claros que orientem o exercício profissional, os conteúdos docentes, as investigações e intervenções acadêmicas ou extra acadêmicas. Esta relativa independência entre os interesses do in- 
vestigador e os problemas em seu contexto não é necessariamente negativa, se considerarmos que, com freqüência, a formulação dos problemas do contexto está sujeita, por sua vez, a interesses políticos e de outras índoles, que não necessariamente colocam o ser humano e seu ambiente como prioridades. Nestes casos, a suposta neutralidade do profissional poderia contrabalançar este tipo de viés perverso. Não obstante, a mesma neutralidade poderia atentar contra a ingerência do investigador como co-autor, negociador ou catalizador de interesses antagônicos, entre cidadãos e entidades com distintos tipos de poder, cujo propósito seria coerente com os princípios da Psicologia Ambiental: conseguir uma harmonia pessoa-ambiente.

2. Fragmentação dos ambientes, assim como dos processos psicológicos, em termos de variáveis, evidenciada a partir da enumeração de fatores estudados com relação a um ou outro objeto. Tal fragmentação é contrária aos requisitos ontológicos, se recordarmos sua aspiração à apreensão molar da transação pessoa-ambiente. Assim, o lugar acaba por reduzir-se ao seu aspecto empírico e a subjetividade dos processos cognitivos, experiências, afetos, comportamentos das pessoas, a imagens, atitudes, preferências, empiricamente mensuráveis para a sua validação empírica. Adicionalmente, encontramo-nos frente aos múltiplos fatores constitutivos dos objetos fragmentados, cujas definições variam segundo os enfoques teórico-metodológicos que os fundamentam. É assim que o estudo da moradia remete desde enfoques cognitivos comportamentais a uma concepção da moradia muito diferente, vista da fenomenologia ou da psicanálise. Como conseqüência deste aspecto, existe nas disciplinas ambientais uma espécie de Torre de Babel conceitual - citando Moraes (1997) - pois os mesmos termos aludem a conteúdos distintos. O termo sustentabilidade é um claro exemplo disto. Se nos colocarmos no lado otimista, diríamos que a diversidade permite abrir o objeto a diferentes perspectivas, o que reduz a hegemonia de uma postura sobre a outra, em nosso caso, a 
dominação da perspectiva positivista ou pós-positivista. Assim, à visão de pessoa e ambiente como realidades objetivas, independentes de nosso modo de acessar o seu estudo, incorporam-se visões como as construtivistas, ainda timidamente presentes na disciplina. Esta postura concebe a relação pessoa-ambiente como totalidade, inseparável e incompreensível à margem das condições do contexto social, político, econômico em que emerge, e em virtude das mudanças no dito contexto, tais relações são igualmente dinâmicas e, portanto, históricas e relativas. Desta maneira, à variedade temática e geográfica mencionada nos estudos psicoambientais, somam-se diferentes opções paradigmáticas. Estas opções são as que fundamentam a definição do objeto de uma ciência, de modo que o mesmo objeto será concebido de distintas maneiras de acordo com o marco meta-teórico em que se baseia. Sem subestimar as vantagens que, desde o nosso ponto de vista, tem a incorporação de distintas perspectivas teórico-epistemológicas como as mencionadas, é algo a ser notado que, dos 332 artigos publicados em E\&B e no JEP desde 1998 até 2002, 305 deles, 175 em E\&B e 128 em JEP, apoiaram-se em teorias inscritas nos paradigmas positivistas ou pós-positivistas. Somente 27 trabalhos ( 8 em E\&B e 19 em JEP), fizeram-no sob outros enfoques, como o transacionalismo, a fenomenologia, o construtivismo social, o enfoque ecológico, a ecoanálise (combinação de enfoque ecológico e psicanálise), o enfoque sociocultural, a teoria fundamentada, a teoria feminista, a teoria crítica. Estes números representam respectivamente $4 \%$ e $13 \%$ dos artigos publicados em cada uma das revistas, em um total de $8 \%$.

3. Tendência à investigação, mas não ao uso e aplicação dos resultados. Neste particular, existe um divórcio entre teoria e prática; entre a academia, âmbito predominante para a produção teórica, e instit uições não acadêmicas ou de orientação fundamentalmente aplicada ou técnica. Assim, enquanto a academia oferece uma informação pouco pertinente e difícil de ser traduzida em termos de 
ação, as instituições não acadêmicas demandam informação cient ífica para a solução de prementes problemas sociais, que a Psicologia Ambiental não está capacitada a prover. Portanto, não é de se estranhar a falta de aplicabilidade e de aplicação dos resultados das investigações, pois muitas delas oferecem o que não se pede e, paralelamente, não estão em condições de trazer o que é requisitado. Esta falta de pertinência dos resultados é contrária aos requisitos de utilidade social da disciplina.

4. Orientação individual nas investigações psicoambientais, não obstante o reconhecimento da natureza social dos processos psicológicos, fica distante da declaração de identidade da Psicologia Ambiental como disciplina psicossocial.

5. Isolamento disciplinar, em que existem escassos vínculos com outras áreas da psicologia como a psicologia clínica, ou comunitária, assim como com algumas disciplinas como a arquitetura ou a planificação urbana, onde a relação resulta mais evidente. Este isolamento disciplinar da Psicologia Ambiental contradiz seu reiterado chamado à interdisciplinaridade.

6. Subestimação da dimensão temporal. A escassa referência a esta dimensão nos estudos psicoambientais foi bem desenvolvida por Moser (2001) e Pinheiro (2002), cada um com uma abordagem diferente ao tema da temporalidade. Para o primeiro, tem a ver com as variações devidas ao desenvolvimento evolutivo das pessoas, enquanto que, para o segundo, a ênfase está no tempo percebido pelas pessoas ou tempo subjetivo, que não corresponde necessariamente ao tempo cronológico. Outra abordagem à dimensão temporal tem a ver com a dinâmica dos eventos intra e interpessoais, sujeitos a mudanças ainda em breves lapsos de tempo cronológico. A relevância da dimensão temporal pede por sua incorporação na definição do objeto de estudo da Psicologia Ambiental, considerando-o tanto em seu componente histórico quanto como subjetivo.

7. Ausência de um pronunciamento ético na literatura sobre ambiente e comportamento (Rivlin, 2002; Saegert \& Winkel, 1990), isto é, sobre posturas e ações orientadas por valores e princípios (Moraes, 
1997). Para Rivlin (2002), uma postura requer que, além de tratar dos assuntos éticos e morais comuns às ciências sociais (como o consentimento dos sujeitos em participar nas investigações, a garantia de sua privacidade, anonimato, segurança), incluir outros específicos à nossa disciplina, dada a temática tratada, os métodos empregados e as implicações, aplicações e publicações dos resultados (Rivlin, 2002, p. 15). Alguns das exigências éticas colocadas pela autora consistem em: a) considerar o valor da investigação, não somente do ponto de vista de sua contribuição teórica ou aplicada, e de seus benefícios para o investigador (ascensão, publicação, etc.), mas também o seu impacto, a curto e longo prazo, sobre os participantes em seus entornos; b) analisar, enquanto profissionais, nossas possibilidades de atuar (incidir) nos temas estudados (por exemplo: falta de moradia, doenças provocadas por condições ambientais desfavoráveis no trabalho, etc.); c) conhecer a disposição dos sujeitos para participar nas investigações, conhecendo os possíveis riscos físicos e emocionais que esta pode acarretar; d) prover informações relativas a organismos e instituições que possam oferecer ajuda com relação às necessidades manifestadas pelos sujeitos no curso da investigação; e) tomar precauções na seleção e aplicação de métodos, a fim de priorizar o respeito à dignidade humana, além das exigências de distância e neutralidade comuns nos métodos de investigação tradicional, tais como a necessidade de manejar situações difíceis surgidas a partir da formulação de perguntas delicadas, etc.

8. Escassa referência à dimensão política, estreitamente relacionada à dimensão ética, à medida que aponta para os produtos e as implicações sociais dos resultados da investigação. Com relação a esta dimensão, diversos autores concordam que toda investigação sofre uma carga de valores e de posturas políticas que, semelhantemente à ética, estão presentes em todas as fases de um projeto (seleção do tema, dos métodos, do tipo de análise e da publicação) (Moraes, 1997; Rivlin, 2002). Isto é particularmente certo na área da Psicologia Ambiental, em que uma distribuição social e econômica do espaço condiciona as oportunidades de acesso ao ambiente (Saegert \& Winkel, 1990). 


\section{Reflexões e recomendações}

Queremos agora resgatar alguns elementos positivos que derivam da análise realizada, assim como propor algumas recomendações adicionais às já expostas, para enfrentar alguns dos problemas mencionados:

1. A imagem transmitida de dispersão dá conta da riqueza do objeto da Psicologia Ambiental que, demarcada dentro de uma agenda que se nutra de e discrimine as demandas locais, regionais e globais poderia potencializar os aportes da disciplina e, por sua vez, enriquecê-la. Os critérios para a seleção dos temas nas ditas agendas devem resultar de negociações das prioridades expressas pelos diversos setores implicados nos ditos temas. Isto garantiria a pluralidade de opiniões e, portanto, os princípios democráticos que devem reger também a produção do conhecimento. Com efeito, o exercício da democracia promove a inclusão de setores que usualmente não têm voz neste e em muitos outros campos mas que, paradoxalmente, conformam o nosso universo de sujeitos de investigação.

2. A recente incorporação de diferentes enfoques em Psicologia Ambiental e as críticas realizadas aos enfoques tradicionais e a outros menos tradicionais, como o transacionalismo (Sánchez \& Wiesenfeld, 2002), deveria constituir outro tema para incluir na agenda de debate, de modo a tentar superar as diferenças paradigmáticas, agora concebidas como posturas irreconciliáveis e transformá-las em novas posturas enriquecidas com o bom e com as limitações das diferentes perspectivas. Considero que o debate sobre este tema é urgente. Em diversas publicações, fiz eco às críticas ao Positivismo e argumentei acerca da pertinência das ditas críticas na Psicologia Ambiental positivista e pós-positivista (Wiesenfeld, 2000, 2001a; Wiesenfeld, Sánchez, \& Cronik, 2002). Isso propiciou experiências baseadas na perspectiva sócio-construtivista e da teoria crítica. $\mathrm{O}$ trabalho mais recente com respeito a este tema foi apresentado com Euclides Sánchez no II Encontro Latinoamericano de Psicologia Ambiental (Sánchez \& Wiesenfeld, 2002). Nessa apresentação, fizemos uma análise crítica do enfoque 
transacional e propusemos uma Psicologia Ambiental construtivista, argumentando que esta perspectiva supera as limitações assinaladas com respeito ao transacionalismo e é coerente com os objetivos formulados pelos pioneiros da Psicologia Ambiental que, do nosso ponto de vista, continuam vigentes.

3. Adicionalmente, as poucas experiências desenvolvidas em Psicologia Ambiental da perspectiva ontológica subjetivista, epistemológica transacional e metodológica qualitativa, que caracterizam o construtivismo, tiveram impacto social favorável, vinculando assim a teoria e a prática, a investigação com a ação.

4. A aplicação dos resultados de nossas investigações deve ser uma preocupação presente desde a formulação do projeto, de modo que contemplemos, desde o seu início, a utilidade potencial dos ditos resultados, assim como a maneira de difundi-los e projetá-los. Esta é uma atividade para a qual estamos pouco preparados, não somente em Psicologia Ambiental, mas também na academia em geral.

5. Finalmente, para finalizar o tema do objeto em Psicologia Ambiental, se a definição do objeto se circunscreve a determinada perspectiva, e as perspectivas diferem em suas dimensões ontológicas, epistemológicas e metodológicas, poderíamos dizer que temos várias psicologias ambientais segundo os diferentes paradigmas em que se fundamentam tais objetos. Como já mostramos, a Psicologia Ambiental dominante foi a positivista, que preferencialmente emprega enfoques cognitivo-comportamentais e metodologias quantitativas. Mas, se queremos contribuir para o desenvolvimento do conhecimento e favorecer nossas condições de vida e do planeta, devemos colocar para dialogar as distintas psicologias ambientais.

\section{Realidades socioculturais e Psicologia(s) Ambiental(ais):}

A segunda pergunta deste tema: "Podem diferentes realidades socioculturais levar a diferentes enfoques de Psicologia Ambiental?” já foi parci- 
almente respondida na primeira parte desta apresentação, mas agora vamos focalizá-la com mais detalhes.

Primeiramente, a maneira como está formulada a pergunta supõe que existem diversas realidades socioculturais, com o que estamos de acordo. Mas pergunta se as ditas realidades podem conduzir ao desenvolvimento de diferentes enfoques da Psicologia Ambiental, e esta segunda parte da pergunta é complexa. Vamos vê-la por partes:

a) a realidade pode levar a diferentes enfoques da Psicologia Ambiental?

b) há, ou pode haver, diferentes enfoques em Psicologia Ambiental, dada a diversidade sociocultural da realidade?

Com respeito à primeira parte do enunciado "A realidade sociocultural pode levar a diferentes enfoques da Psicologia Ambiental?”, significa: tem a realidade a potência de fazer algo ela mesma? Podemos fazer diferentes leituras. Se nos basearmos na análise sobre o desenvolvimento da Psicologia Ambiental apresentado, notamos que o seu objeto não se diferenciou precisamente segundo o contexto. Vimos que dentro de um mesmo país há diferentes maneiras de estudar um ambiente ou processo, e que elas coincidem com os modos de concepção e aproximação ao dito objeto em outros países e continentes. Considero que isto obedece à noção de realidade adotada pelo paradigma positivista em que se apoiaram grande parte dos trabalhos na disciplina. Este paradigma concebe a realidade em termos de variáveis que fragmentam a totalidade, o que permite que incidam no segundo elemento do binômio do objeto da Psicologia Ambiental, isto é, as pessoas igualmente concebidas em suas qualidades perceptíveis com os métodos apropriados.

Isto não quer dizer que as diferentes realidades socioculturais não impliquem distintos modos de enfocar o objeto da Psicologia Ambiental, mas que as premissas da Psicologia Ambiental positivista descontextualizam os objetos, assumindo a universalidade e ahistoricidade do conhecimento produzido. 
A resposta neste caso não depende, então, da realidade sociocultural mas do enfoque. Com isto estamos dizendo que há enfoques que não levam em consideração as características do contexto e, baseando-nos neles, diríamos que não são as realidades que propiciam os enfoques, mas que são os enfoques que constróem realidades. Reformularíamos então o enunciado da segunda pergunta dizendo: Podem os diferentes enfoques da Psicologia Ambiental construir diferentes realidades socioculturais? E a resposta seria afirmativa.

Se nos centrarmos agora na segunda parte do enunciado: Pode haver diferentes enfoques em Psicologia Ambiental, dada a diversidade sociocultural da realidade?, necessitamos então esclarecer o que entendemos por diversidade sociocultural da realidade.

Assumimos que os fatores socioculturais da realidade são alguns dos elementos constitutivos do contexto de que formam parte, de modo que preferimos referir-nos ao contexto como um conceito mais integrador.

Quando se fala na influência do contexto, estamos aludindo a um conjunto de condicionantes ecológicos, isto é, sociais, econômicos, políticos, culturais, geográficos, históricos, na geração dos significados que as pessoas elaboram acerca de suas realidades. Todo significado está vinculado ao contexto em que é gerado, de modo que o contexto marca o caráter local da relação pessoa ambiente. Com isto queremos destacar que as ditas relações são significadas com base nos condicionantes mencionados.

Podemos dizer, então, seguindo Strauss e Corbin (1990), que o contexto é um conjunto de propriedades de um fenômeno, evento, incidente, com o que se relacionam, em um espaço e tempo determinados, diversas ações e interações, e podemos acrescentar, interpretações. Dito de outro modo, é no marco das características locais do contexto que os grupos ou comunidades interpretam sua vida cotidiana e orientam suas práticas sociais. $\mathrm{E}$ é, precisamente, essa confluência de condições locais, com a sua correspondente colocação espaço-temporal, que conforma a diversidade dos contextos ou, parafraseando o enunciado de nossa pergunta, a diversidade sociocult ural da realidade. 
Dada a multiplicidade de fatores que, como vimos, as integram, podemos dizer que se trata de realidades complexas, e como as condições em questões são cambiantes, também podemos dizer que são realidades dinâmicas e relativas.

Não se trata, portanto, de adotar enfoques, em que cada um responda às características das realidades locais, mas de identificar enfoques que reconheçam tais qualidades. Neste sentido, e reiterando a resposta ao primeiro enunciado da pergunta, não seriam as realidades as construtoras de enfoques mas antes que, de acordo com os enfoques adotados, poderíamos abordar a dita diversidade de um ou outro modo, resgatando em seus postulados os aspectos da realidade que se tenta enfatizar e os modos de concebê-la.

De acordo com Pinheiro (2002), na atualidade, os estudos no campo do compromisso ambiental buscam uma maior contextualização, à medida que incluem bases culturais e históricas dos valores das pessoas, aspectos afetivos, ideologias políticas e visões do mundo.

Esperemos que esta inquietação se translade também para os demais temas de interesse para a disciplina.

Wiesenfeld, E. (2005). Environmental psychology and the diverse human realities. Psicologia USP, 16(1/2), 53-69.

\begin{abstract}
This article is based on the analysis of the journals Environment and Behavior, Journal of Environmental Psychology, of Latin-American congresses, studies, and networks. It argues that the definition of the object circumscribed to certain perspectives that differ in their ontological, epistemological and methodological dimensions, lead to many Environmental Psychologies. In order to contribute to the development of knowledge and favor our life conditions and the conditions of the planet, we must foster the dialogue between the different environmental psychologies. It concludes that the angle adopted leads to the analysis of diversity, rescuing or not, in its postulates, the aspects of reality that one tries to emphasize and the ways to conceive it.
\end{abstract}




\section{Esther Wiesenfeld}

Index terms: Environmental psychology. Object. Content analysis.
Journals.

Wiesenfeld, E. (2005). La psychologie de l'environnement et les différentes réalités humaines. Psicologia USP, 16(1/2), 53-69.

Résumé: Cet article fonde les réponses à ces questions sur l'analyse des périodiques Environment and Behavior, Journal of Environmental Psychology, et sur celle des congrès, des études et des réseaux latinoaméricains. Il considère que la définition de l'objet, circonscrite à une perspective déterminée que diffèrent quant à leurs dimensions ontologiques, épistémologiques et méthodologiques, il y aurait différentes Psychologies de l'Environnement. Il recommande que, pour contribuer au développement de la connaissance et favoriser nos conditions de vie ainsi que celles de la planète, nous devons faire interagir les différentes psychologies de l'environnement. Il en conclut que l'optique adoptée mènerait à aborder la diversité, récupérant ou non, dans ses postulats, les aspects de la réalité que l'on essaie de mettre en évidence ainsi que les modes de la concevoir.

Mots-clés: Psychologie de l'environnement. Objet. Analyse de contenu. Périodiques.

\section{Referências}

Moraes, R. (1997). Meio ambiente e ciências humanas. Sao Paulo: Hucitec.

Moser, G. (2001). Psicologia ambiental no novo milênio: integrando a dinâmica cultural e a dimensao temporal. In E. Tassara (Org.), Panoramas interdisciplinares para uma psicologia ambiental do urbano (pp. 189-210). São Paulo: EDUC / FAPESP.

Moser, G. (2002). La psicología ambiental: del análisis a la intervención dentro de la perspectiva del desarrollo sustentable. In J. Guevara \& S. Mercado (Coords.), Temas selectos de psicología ambiental (pp. 235-262). México: UNAM / Greco: Fundación UNILIBRE.

Pinheiro, J. (2001). (Um poco da) psicologia ambiental no Brasil: identidade, incertezas, perspectivas. In E. Tassara (Org.), Panoramas interdisciplinares para uma psicologia ambiental do urbano (pp. 11-26). São Paulo: EDUC / FAPESP. 
Pinheiro, J. (2002). Comprometimento ambiental: perspectiva temporal e sustentabilidade. In J. Guevara \& S. Mercado (Coords.), Temas selectos de psicología ambiental (pp. 463-483). México: UNAM / Greco: Fundación UNILIBRE.

Pol, E. (2001). Ejes de tensión y nueva agenda para la psicología ambiental. Una perspectiva europea. In E. Tassara (Org.), Panoramas interdisciplinares para uma psicologia ambiental do urbano (pp. 51-70). São Paulo: EDUC / FAPESP.

Rivlin, L. (2002). The ethical imperative. In R. Bechtel \& A. Churchman (Eds.), Handbook of environmental psychology (pp. 15-27). Nova York: John Wiley and Sons.

Saegert, S., \& Winkel, G. (1990). Environmental psychology. Annual Review of Psychology, 41, 441-477.

Sánchez, E., \& Wiesenfeld, E. (2002). El construccionismo como otra perspectiva metateórica para la producción del conocimiento en psicología ambiental. In J. Guevara \& S. Mercado (Coords.), Temas selectos de psicología ambiental (pp. 930). México: UNAM / Greco: Fundación UNILIBRE.

Strauss, A., \& Corbin, J. (1990). Basic of qualitative research. Newbury Park, CA: Sage.

Wiesenfeld, E. (2000). La autoconstrucción: un estudio psicosocial del significado de la vivienda. Caracas, Venezuela: CONAVI.

Wiesenfeld, E. (2001a). La proble mática ambiental desde la perspectiva psicosocial comunitaria: hacia una psicología ambiental del cambio. Medio Ambiente y Comportamiento, 2(1), 1-19.

Wiesenfeld, E. (2001b). Tendencias y perspectivas de desarrollo en psicología ambiental. In E. Tassara (Org.), Panoramas interdisciplinares para uma psicologia ambiental do urbano (pp. 27-50). São Paulo: EDUC / FAPESP.

Wiesenfeld, E., Sánchez, E., \& Cronick, K. (2002). La intervención ambiental participativa: fundamentos y aplicaciones. In J. Guevara \& S. Mercado (Coords.), Temas selectos de psicología ambiental (pp. 377-411). México: UNAM / Greco: Fundación UNILIBRE.

Recebido em 5.04.2004

Revisto e encaminhado em 23.02.2005

Aceito em: 7.03.2005 